\title{
FREQUENCY OF EARTHQUAKES IN CALIFORNIA*
}

\author{
By B. Gutenberg and C. F. Richter
}

Estimates of the frequency of destructive shocks in California have usually been based on the very imperfect historical record. The present note attempts to revise these estimates by statistical comparison of earthquake frequency in California with that of the world as a whole.

The necessary discrimination between larger and smaller shocks must be based on instrumental records and not on reports of destructive effects, since submarine shocks and those of unpopulated regions must be considered. This is done by means of the instrumental magnitude scale originally set up for California ${ }^{1}$ and later extended to shocks in all parts of the world. ${ }^{2}$ The magnitude $M$ of an earthquake was originally defined as proportional to the logarithm of the maximum trace amplitude on the seismogram of a standard torsion seismometer distant 100 kilometers from the epicenter. This applies to earthquakes at normal shallow depth (deep-focus earthquakes have not been observed in the California region).

The magnitude scale is chosen to make $M=0$ correspond to the smallest instrumentally recorded shocks. It is found that:

\footnotetext{
$M=2$ corresponds to the smallest shocks ordinarily reported felt.

$M=4.5$ corresponds to the smallest shocks causing slight damage.

$M=6 \quad$ corresponds to moderately destructive earthquakes.

$M=8.5$ corresponds to the largest recorded shocks.
}

Since 1921, the following shocks in the California-Nevada region have had magnitude 7 or greater:
1922 January 31
$\mathrm{M}=7.3$ Off the north coast.
1923 January 22
7.1 Off the north coast.
1927 November 4
7.0 Off Point Arguello.
1932 December 20
7.3 West-central Nevada.
1934 December 31
7.0 South of the Imperial Valley.

In the present century, two shocks in the same region have exceeded magnitude $7 \frac{1}{2}$ :

1906 April 18

1915 Oetober 2

$$
\begin{aligned}
& M=81 / 4 \text { Central California. } \\
& 73 / 4 \text { North-central Nevada. }
\end{aligned}
$$

In order to deal more precisely with smaller shocks an area for statistical study was delimited, including most of southern California, a small part of adjacent Mexico, and the Owens Valley. This area is favorably situated with respect to the eight stations of the local network. Since 1921, the following shocks in this selected area have had magnitude 6 to $6 \%$ :

$\begin{array}{lrl}1922 \text { March } 10 & M=61 / 2 & \text { San Andreas fault near Cholame. } \\ 1923 \text { July } 22 & 61 / 4 & \text { San Bernardino, Redlands. } \\ \text { 1925 June 29 } & 61 / 4 \text { Santa Barbara. } \\ 1927 \text { September 17 } & 6 & \text { Bishop; northern Owens Valley. } \\ 1933 \text { March 10 } & 61 / 4 & \text { Long Beach. }\end{array}$

* Manuscript received for publication May 18, 1944.

C. F. Richter, Bull. Seism. Soc. Am., 25:1-32, 1935.

2 B. Gutenberg and C. F. Richter, Gerlands Beitr. z. Geophysit, 47:73-131, 1936. 


$\begin{array}{lll}\text { 1934 June 7 } & 6 & \text { San Andreas fault near Parkfield. } \\ 1937 \text { March 25 } & 6 & \text { San Jacinto fault. } \\ 1940 \text { May 18 } & 6 \frac{3}{4} \text { Imperial Valley. } \\ \text { 1941 June 30 } & 6 & \text { Off Santa Barbara. } \\ \text { 1941 September 14 } & 6 & \text { Northern Owens Valley. } \\ \text { 1942 October 21 } & 6 \frac{1}{2} 2 & \text { San Jacinto fault; Borego Valley. }\end{array}$

Of the larger shocks, the selected area includes that of November 4, 1927, magnitude 7.0. That of December 31, 1934, is the largest of a very numerous series of shocks south of the Imperial Valley; the selected area has been taken so as to exclude these. The 11 listed shocks for 22 years give an average of exactly 0.5 annually.

For the period January, 1934-May, 1943 inclusive, the following numbers $N$ of shocks in the selected area were observed with magnitudes as given to the nearest half unit:

$\begin{array}{cccccccc}M= & 6.5 & 6 & 55 & 5 & 4.5 & 4 & 3.5 \\ N= & 2 & 5 & 13 & 32 & 108 & 311 & 579+ \\ \text { Annual mean } 0.2 & 0.5 & 1.4 & 3.4 & 11.5 & 33.0 & 62+\end{array}$

Listing is complete for magnitude 4 and higher; for magnitude 3.5, various estimates indicate that the count is roughly 20 per cent too small. Supposing

$$
\log N=a+b(8-M)
$$

a least-squares solution gives

$$
a=-2.04 \pm 0.09, \quad b=0.88 \pm 0.03
$$

The magnitudes given for the larger shocks have been taken from an investigation of the larger shocks of the whole world, now nearing completion. From the same source are extracted the following statistics.

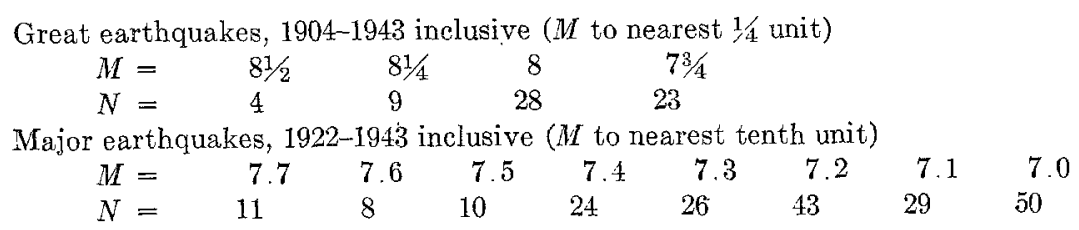

To these a formula of type (1) has been fitted, corresponding to an interval of onetenth unit, giving

$$
a=-0.76 \pm 0.05, \quad b=1.12 \pm 0.11
$$

Excluding magnitudes $81 / 4$ and $81 / 2$, which are represented by very small numbers, the result becomes

$$
a=-0.65 \pm 0.09, \quad b=0.97 \pm 0.15
$$

This gives 109 shocks annually of magnitude 6 to $63 / 4$ (more precisely, 5.9 to 6.8 inclusive). A direct count for five years gave 117 per year.

At about $39^{\circ}-40^{\circ} \mathrm{N}$, the San Andreas fault zone and other parallel structures strike out to sea. On the northwestern prolongation of this trend is a very active zone, for which a separate count has been made. These shocks are also included in the totals for the California-Nevada region. 
The chief statistical results may now be summarized:

\begin{tabular}{|c|c|c|c|}
\hline & \multicolumn{3}{|c|}{ Magnitude, $M$} \\
\hline & $\begin{array}{c}73 / 4 \text { and greater } \\
1904-1943\end{array}$ & $\begin{array}{c}7-7.7 \\
1922-1943\end{array}$ & $\begin{array}{c}6-63 / 4 \\
1922-1943\end{array}$ \\
\hline World. & 67 & 197 & 2,500 (est.) \\
\hline California-Nevada. & 2 & 5 & $33 ?$ \\
\hline Southern California. & 0 & 1 & 11 \\
\hline North coast... & 0 & 2 & 12 \\
\hline
\end{tabular}

In the last column, the number 2,500 for the world is estimated from the calculated and partly counted values of 109 and 117 annually. The number 33 ? for CaliforniaNevada is somewhat uncertain since in the earlier years, of the period a few. shocks in the Nevada region may have been missed. All the other numbers given represent complete counts.

It appears that the selected southern California area (including the Owens Valley) has about one-half of one per cent of the seismic activity of the globe, that is, about one-half of one per cent of the shocks in any given range of magnitude. The activity off the north coast is slightly greater, although the area of the active region is much less since the shocks occur in a comparatively narrow belt.

In the three columns the numbers given for the entire California-Nevada region are $3,2.5$, and 1.3 per cent of those for the world. The lower figures for smaller magnitudes probably represent an exceptional lowering of activity in central California and in Nevada following the great earthquakes of 1906 and 1915. A value of 2.5 per cent may be taken as representative. Applying this to the totals for the world, the data would call for 4 great earthquakes of magnitude $73 / 4$ and greater, and 22 additional major earthquakes (magnitudes 7-7.7) in the California-Nevada region per century. The southern California and Owens Valley selected area should have about one-fifth of these, or say 1 great shock and 4 or 5 additional major earthquakes per century.

In the past hundred years 4 great earthquakes are known to have taken place in California and Nevada. In addition to those of 1906 and 1915 noted previously, there were the earthquake of 1857 on the San Andreas fault in southern California and the Owens Valley earthquake of 1872. Both of these thus fall within the selected area.

Historical information on shocks of lesser magnitude, even when large enough to be classifiable as major earthquakes, is very imperfect; but a sufficient number of probable instances are known to make it likely that the mean figures, per century, of 22 for the large region and 4 or 5 for the smaller area are not excessive.

Equations of the form (1) represent the observations over nearly the whole range for which there are reliable data, say from magnitude 3 to magnitude 81/2. Extrapolation beyond these limits appears to fail. ${ }^{3}$ The evidence is that neither extremely great shocks nor extremely small shocks are as frequent as the equation would indicate. In order to include very small shocks, those of the area between limits $331 / 2^{\circ}-$ $34 \frac{1}{2} \mathrm{~N}, 117^{\circ}-118^{\circ} \mathrm{W}$, near Pasadena, were counted. Here at least 50 shocks of magnitudes 2 and $21 / 2$ were found to occur annually, while the numbers in larger magnitudes were uniformly about 6 per cent of those for the southern California

\footnotetext{
${ }^{3}$ B. Gutenberg and C. F. Richter, "Seismicity of the earth," Geol. Soc. Am. Special Papers, No. 34 (1941).
} 
selected area. This would indicate more than 850 in magnitudes 2 and $21 / 2$ for the selected area, which, added to the number 360 calculated for magnitudes 3 and greater from (1) and (2), gives an estimated total of about 1,200 shocks annually which are large enough to be felt. The corresponding estimated number for the California-Nevada area is more than 5,000, and that for the world, more than 250,000 . Note that about two-thirds of these are in the smallest magnitudes, and that these estimates do not include the swarms of small earthquakes that always occur as aftershocks following a major seismic event.

In the continental United States outside of the California-Nevada region, no shock of magnitude 7 or greater has originated in the period studied (since 1903), although a few large shocks in Canada and the Atlantic Ocean have been felt in the United States. Since 1921, 5 shocks of magnitude 6 and greater have occurred ( 3 in Montana, 1 each in Utah and Texas). This compares with 33 shocks in the California-Nevada area in the same period and magnitude range. Moreover, these 5 are all in the Cordilleran province, no large shocks having occurred to the eastward -although the only great earthquake east of Nevada for which there is historical evidence was in Missouri (1811). The magnitude of the Charleston (South Carolina) earthquake of 1886 was definitely lower.

This gives the California-Nevada region about 90 per cent of the seismic activity of the United States - a result based mainly on present conditions, but in good agreement with historical data. However, even historical time is very short geologically, and evidence of recent changes in the activity of some other parts of the world is reasonably good. Consequently, it must not too hastily be assumed that the numerical proportions now found will remain unaltered in the future. Especially for large shocks, we are dealing statistically with small numbers; the danger of carrying conclusions too far in such cases is well known. Thus, the expected occurrence of about four great earthquakes per century in the California region by no means excludes the possibility that double that number might occur in a given century, or that a whole century might pass without even one. Further, the events are not strictly independent. A great shock, such as that of 1906, represents a regional release of strain; after the immediate aftershocks have subsided, it may be expected to be followed by a period of abnormal quiet, as is probably now the condition in central California.

With these qualifications, it remains true that great shocks may be expected to occur in California in the future, as in the past. In the long run, they should be distributed rather evenly over the principal active zones. It is worth noting that great shocks are to be looked for only in association with the major active faults and structures, such as the San Andreas fault zone and the trough of the Owens Valley. The other faults and active structures are characterized at most by moderately destructive earthquakes like those at Santa Barbara and Long Beach.

California Institute of Technology

Pasadena, Caljfornia

(Balch Graduate School of the Geological Sciences, Contribution No. 369) 